\title{
DIREITOS HUMANOS E EDUCAÇÃO: COMO SE EXPRESSAM DCN E NA BNCC
}

\author{
HUMAN RIGHTS AND EDUCATION: HOW ARE THEY EXPRESSED IN THE DCN AND BNCC? \\ DERECHOS HUMANOS Y EDUCACIÓN: CÓMO SE EXPRESAN EN LAS DCN Y BNCC
}

\author{
Luana Hillesheim \\ Mestranda em Educação pelo Programa de Pós-Graduação em Educação da Universidade Regional de \\ Blumenau, Blumenau, Santa Catarina, Brasil. E-mail: luaanahillesheim@gmail.com \\ ORCID: https://orcid.org/0000-0002-7223-4813, \\ E-mail: luaanahillesheim@gmail.com
}

\begin{abstract}
Juliana Elis dos Santos Hoffmann
Doutoranda em Educação pelo Programa de Pós-Graduação em Educação da Universidade Regional de Blumenau, Blumenau, Santa Catarina, Brasil. E-mail: julianaeshoffmann@hotmail.com ORCID: https://orcid.org/0000-0001-5059-1679,
\end{abstract}

\section{Karina Albuquerque Barreto}

Mestranda em Educação pelo Programa de Pós-Graduação em Educação da Universidade Regional de Blumenau, Blumenau, Santa Catarina, Brasil. E-mail: ka.barreto@gmail.com

ORCID: https://orcid.org/0000-0003-4123-5394,

\author{
Andrea Soares Wuo \\ Doutora em Educação pela Pontifícia Universidade Católica de São Paulo. Docente na Universidade \\ Regional de Blumenau, Blumenau, Santa Catarina, Brasil. E-mail: awuo@furb.br \\ ORCID: https://orcid.org/0000-0003-2110-7184,
}

\begin{abstract}
Resumo
Nas sociedades contemporâneas, os direitos humanos são meios de garantir dignidade, liberdade e igualdade aos seres humanos. Como imperativo de construção de um mundo com menos desigualdade, no qual se respeitam as diversidades como fundamento da dignidade humana, este artigo tem como objetivo principal refletir sobre as relações entre os direitos humanos e a educação a partir das Diretrizes Curriculares Nacionais e da Base Nacional Comum Curricular; como objetivo específico, pretende analisar o entendimento que esses documentos apresentam sobre os direitos humanos. Este trabalho em educação, de abordagem qualitativa, utilizou a pesquisa documental. Mediante análise dos documentos curriculares, observou-se que a educação é compreendida por um viés dos direitos humanos, como promotora de tais direitos, concepção amplamente disseminada nos textos. Embora os documentos conjuminem educação e direitos humanos, há diferenças entre ambos, os quais expressam particularidades no que diz respeito aos contextos de produção, bem como às compreensões dos modos como os direitos humanos são pensados na e para a educação básica.
\end{abstract}

Palavras-chave: BNCC; direitos humanos; Diretrizes Curriculares Nacionais; Educação em Direitos Humanos.

Abstract
In contemporary societies, human rights are a means to ensure human beings' dignity, freedom, and equality.
As an imperative of building a world with less inequality, in which diversity is respected as the foundation of
human dignity, this article aims to reflect on the relationship between human rights and education based on 
the Diretrizes Curriculares Nacionais and the Base Nacional Comum Curricular; as a specific objective, it intends to analyze the understanding that these documents present about human rights. This work in education, with a qualitative approach, used documentary research. By curriculum documents analyzes, it was observed that education is understood from a human rights perspective, and as a promoter of such rights, a concept widely disseminated in the texts. Although the documents combine education and human rights, there are differences between the two, which express particularities with regard to the contexts of production, as well as the understandings of the ways in which human rights are thought of in and for basic education.

Keywords: BNCC; Human Rights; National Curriculum Guidelines; Human Rights Education.

\section{Resumen}

En las sociedades contemporáneas, los derechos humanos son medios que garantizan la dignidad, la libertad y la igualdad a los seres humanos. Como imperativo para construir un mundo con menos desigualdad, en el que se respete la diversidad como fundamento de la dignidad humana, este artículo tiene como objetivo reflexionar sobre la relación entre los derechos humanos y la educación, a partir de las Directrices Curriculares Nacionales y de la Base Nacional Curricular Común; como objetivo específico, pretende analizar la visión que estos documentos presentan sobre los derechos humanos. Este trabajo en educación, con enfoque cualitativo, utilizó la investigación documental. A través del análisis de los documentos curriculares, se observó que la educación es comprendida desde la perspectiva de los derechos humanos y como promotora de tales derechos, concepción ampliamente difundida en los textos. Aunque los documentos puedan unir educación y derechos humanos, existen diferencias entre ambos, los cuales expresan particularidades en lo que a sus contextos de producción se refiere y a las formas en que conciben los derechos humanos en y para la educación básica.

Palabras-clave: BNCC; Derechos humanos; Directrices Curriculares Nacionales; Educación en Derechos Humanos.

\section{INTRODUÇÃO}

O começo de uma nova era para o ser humano, o qual passou a ser reconhecido em sua integralidade, aconteceu, sobretudo, a partir de 1948, com a Declaração Universal dos Direitos Humanos (DUDH). Mais do que um documento adotado pela Organização das Nações Unidas (ONU), a DUDH veio afirmar diversos princípios universais em favor dos seres humanos, até então ignorados ou não praticados, ou como diria Piovesan (2018, p. 62): “a Declaração consolida a afirmação de uma ética universal, ao consagrar um consenso sobre valores de cunho universal, a serem seguidos pelos Estados".

Assim, a DUDH impulsionou os direitos humanos a revolucionarem o mundo, agregados a todas as áreas nas quais houvesse interação humana. Inclusive, é com ela que, segundo Piovesan (2018), os direitos humanos passaram a ser universais, interdependentes e indivisíveis, isto é, alcançaram toda pessoa, sendo esta titular exclusiva de todos os direitos (civis, econômicos, políticos, sociais, dentre outros), e considerando 
que, se um direito é violado, outros são concomitantemente afetados. A importância desse discurso sociopolítico é reconhecer que, com a DUDH, os estados e a comunidade internacional assumiram, paulatinamente, um senso de consciência ética sobre os direitos inerentes ao indivíduo, independentemente das circunstâncias sociopolíticas e culturais.

Os direitos humanos são alicerce de uma cultura democrática, amparados em valores éticos, como liberdade, diálogo e participação. Neste sentido, são elementos básicos de uma cidadania que envolve atitudes de respeito à dignidade das pessoas, nas dimensões individuais e coletivas; também com o reconhecimento do outro e sua forma de entender o mundo (RAYO, 2013; BENEVIDES, 2007). Piovesan (2018) esclarece que o princípio básico dos direitos humanos é a dignidade humana, posto que o ser humano é considerado "[...] um ser essencialmente moral, dotado de unicidade existencial e dignidade, esta como valor intrínseco à condição humana" (PIOVESAN, 2018, p. 216).

Entretanto, ainda que, hodiernamente, seja um imperativo ético universal a defesa e a promoção dos direitos humanos, estes são diariamente transgredidos de diferentes maneiras. Não é difícil admitir que subsista um discurso retórico sobre direitos humanos vindo de toda a parte. A partir de viés teórico a respeito dos direitos humanos, Candau et al. (2014, p. 30) afirmam que "a luta para estabelecê-los firmemente na consciência dos indivíduos e dos povos passa obrigatoriamente por processos educativos". Aliás, a ideia da educação como componente essencial para os direitos humanos é encontrada no art. 26 da DUDH, quando expressa:

\footnotetext{
A educação será orientada no sentido do pleno desenvolvimento da personalidade humana e do fortalecimento do respeito pelos direitos humanos e pelas liberdades fundamentais. A educação promoverá a compreensão, a tolerância e a amizade entre todas as nações e grupos raciais ou religiosos, e coadjuvará as atividades das Nações Unidas em prol da manutenção da paz (ONU, 1948).
}

Nota-se uma relação indissociável entre a educação e os direitos humanos: quer seja a educação enquanto um direito, quer seja a educação um meio para efetivação dos direitos humanos. Quanto a esta última abordagem, os processos educativos contribuem para o desenvolvimento da consciência acerca dos direitos humanos, pela mudança de mentalidade a partir da compreensão de valores e princípios éticos universais intrínsecos aos seres humanos. Candau et al. (2014) afirmam que um dos pressupostos da educação em direitos humanos é "[...] o reconhecimento do outro como sujeito de direito e ator 
social” (CANDAU et al., 2014, p. 34). Para transformar a realidade é imprescindível assentir para a força da singularidade, o respeito à diferença e à diversidade.

No tocante à educação em e para direitos humanos no Brasil, existem diversos dispositivos normativos e documentos políticos educacionais que têm direcionado ações e políticas públicas sobre a temática, tais como o Plano Nacional de Educação em Direitos Humanos (PNEDH), o Programa Nacional de Direitos Humanos (PNDH-3), instituído pelo decreto n. ${ }^{\circ}$ 7.037/2009, bem como o Plano Nacional de Educação (PNE), aprovado pela lei n. ${ }^{0} 13.005 / 2014$.

Esses instrumentos são indispensáveis e fundamentam quaisquer outros documentos e dispositivos legais e políticos estabelecidos no país. Logo, ao sopesar a relevância dos processos curriculares, pedagógicos e/ou educacionais, a fim de verificar sua sintonia com esses instrumentos, este artigo visa apresentar reflexões acerca dos direitos humanos e a educação a partir de documentos educacionais, quais sejam: as Diretrizes Curriculares Nacionais (DCNs) (BRASIL, 2013) e a Base Nacional Comum Curricular (BNCC), homologada pelo Ministério da Educação, por meio da portaria n. 1.570/2017 (BRASIL, 2017).

Deste modo, em uma abordagem qualitativa, esta pesquisa documental em educação objetiva principalmente refletir sobre as relações entre os direitos humanos e a educação a partir das DCNs e da BNCC; como objetivo específico, analisar qual o entendimento que esses documentos apresentam sobre os direitos humanos. Para tanto, o artigo inicia com um resgate histórico e conceitual sobre as relações entre direitos humanos e educação.

Um levantamento na base de dados da Scielo evidenciou poucas obras relacionadas ao tema direitos humanos, educação e currículo, dentre as quais apenas dois artigos realizaram análise documental. Ramos (2011) analisa como a diferença se articula no processo de constituição do currículo de educação em direitos humanos, por diversos documentos: Plano Nacional de Educação em Direitos Humanos; Subsídios para a elaboração das diretrizes gerais da Educação em Direitos Humanos; Projeto capacitação de Educadores da Rede Básica de Ensino em Educação em Direitos Humanos; Direitos Humanos: capacitação de educadores. Além disso, realizou entrevistas com pessoas que protagonizaram a elaboração de alguns desses documentos. Ramos (2011) afirma a educação em direitos humanos como um instrumento para transformar a sociedade, 
consolidação da democracia, promoção da cidadania e como estratégia para a difusão da cultura em direitos humanos. Problematiza, em sua conclusão, que os direitos humanos não devem ser abordados apenas como um conjunto de normativas, mas a partir de uma experiência a ser construída.

Fernandes e Paludeto (2010) analisam os direitos humanos, e como aparecem nos Parâmetros Curriculares Nacionais e no Plano Nacional de Educação em Direitos Humanos. Sobres estes, as autoras mencionam os temas transversais (enfatizam o trabalho com valores), como a educação em direitos humanos contribui para ações que os promovem e protegem, e, a educação como um direito. Ademais, as autoras afirmam que a formação de professores para/em direitos humanos ainda é muito recente, porque são poucas as temáticas relacionadas na formação docente. Na conclusão de seu estudo, mencionam que a educação orientada para os direitos humanos não está devidamente inserida no currículo escolar. Diante desse levantamento, as autoras citadas contribuem para refletir acerca dos direitos humanos, e da educação neste sentido. Como não se verificou nenhum artigo que abordasse as relações entre direitos humanos e educação, o levantamento evidenciou a relevância de tal pesquisa, pois, existem poucas produções que discutem relações entre direitos humanos e educação a partir de documentos norteadores das políticas curriculares nacionais.

\section{Direitos humanos e educação}

A Segunda Guerra Mundial (1939-1945) apresentou a tirania do Estado representada pela seleção, categorização e invalidação do ser humano, que respaldou o extermínio de milhões de pessoas de forma cruel, marcada pelo uso de seres humanos em experimentos, torturas, mortes violentas e toda forma de degradação. Essas atrocidades introjetaram na comunidade internacional a necessidade de atentar ao conceito de direitos humanos, para limitar as ações do Estado e inibir massivas formas de violações.

Nesse processo, em 1945, cria-se a Organização das Nações Unidas (ONU), marco de uma nova fase de cooperação internacional em defesa dos direitos humanos, para torná-los válidos para todos os seres humanos, através da Declaração Universal dos Direitos Humanos (DUDH), aprovada em 1948, por 48 Estados, e considerada instrumento global emancipador dos direitos humanos. 
A partir de sua redação, os direitos humanos tornam-se universais e indivisíveis, características que demarcam sua concepção contemporânea — visto que os direitos civis e políticos constam também na Declaração dos Direitos dos Homens e dos Cidadãos, de 1789 -, e reiteram a importância dos direitos fundamentais, considerados imprescindíveis em sua integralidade para a garantia da dignidade humana. Aliás, Cury (2013) afirma que para avançar no conceito de cidadania é necessária a universalização dos direitos humanos, isto é, o caráter essencial dos direitos humanos de modo a alcançar qualquer indivíduo, garantindo-lhe proteção e defesa para ser, de fato, sujeito de direitos e deveres, internacionalmente reconhecido.

Em seu Artigo $1^{\circ}$, a DUDH, ao enfatizar "igualdade em dignidade e direitos", inibe possíveis tentativas de hierarquizar ou desvaler qualquer direito, as quais implicariam negativamente a concretude da dignidade humana. Sobre o assunto, Rodriguez (2002) explica que a Declaração coloca os direitos fundamentais no mesmo patamar, o que significa integralidade e indivisibilidade dos direitos humanos. Diz Rodriguez:

Devemos partir do princípio de que todos os direitos são fundamentais, portanto, não devemos estabelecer nenhum tipo de hierarquia entre eles e, muito menos, crer que uns são mais importantes que outros. É difícil pensar em ter uma vida digna se não desfrutamos de todos os direitos (RODRIGUEZ, 2002, p. 20).

Cury (2013) menciona que "a igualdade ainda é o norte pelo qual as pessoas lutam para ir reduzindo as desigualdades em favor de maior igualdade" (CURY, 2013, p. 199). Segundo o autor, é preciso defender a igualdade como princípio dos direitos humanos, da cidadania e da modernidade.

Na linha histórica dos direitos humanos, embora a DUDH seja datada em 1948, a nação brasileira se manteve inerte ao movimento internacional de reconhecimento dos princípios da dignidade humana, como também infringia os direitos humanos diante do regime ditatorial que perdurou até a década de 1980. Somente a partir do movimento de redemocratização, iniciado na década de 1970 com pressão da população, que se desenvolveu o debate para elaboração de uma nova Constituição Federal (CF), a qual trouxesse novos valores à sociedade, posteriormente promulgada em 1988.

Ressalte-se que dois anos antes da nova CF, a resolução 41/128, da Assembleia Geral das Nações Unidas, adotou, em 4 de dezembro de 1986, a redação que configuraria o 
reconhecimento do direito ao desenvolvimento enquanto direito humano, evidenciando, no artigo $3^{\circ}$, a responsabilidade do Estado em proporcionar as condições para sua efetividade. Conjuntamente, o artigo $8^{\circ}$ conferiu o acesso à educação como um dos componentes do direito ao desenvolvimento.

Com isso, a Carta Magna de 1988 (BRASIL, 1988) fez emergir a cidadania, como também absorveu os princípios da Declaração de 1948, valendo-se dos direitos humanos nas relações internacionais, de acordo com art. $4^{\circ}$ (BRASIL, 1988), e adotou a dignidade da pessoa humana como fundamento do Estado Democrático de Direito, conforme art. $1^{\circ}$ (BRASIL, 1988). Ademais, em consonância à resolução 41/128, a CF/1988 trouxe em seu artigo $6^{\circ}$ a educação no rol dos direitos sociais, atribuindo à União, aos Estados e aos Municípios a responsabilidade pelos meios de acesso "à cultura, à educação, à ciência, à tecnologia, à pesquisa e à inovação", segundo o art. 23 (BRASIL, 1988); e conferindo a gratuidade do ensino público, consoante artigo 206 (BRASIL, 1988).

Acerca do rol de direitos que começaram a ser afirmados internacionalmente mediante a DUDH, embora ocorra o debate sobre a classificação geracional dos direitos fundamentais, essa divisão (didática) será atrelada a esta pesquisa de maneira a considerar o percurso histórico de evolução e reconhecimento dos direitos humanos até a terceira dimensão dos direitos fundamentais, por ser amplamente conhecida e admitida. Nesta perspectiva, Peixinho e Ferraro (2008) abordam que a Declaração dos Direitos dos Homens e dos Cidadãos (1789) data o reconhecimento da primeira dimensão dos direitos fundamentais individuais, apresentados pelo reclame dos direitos civis e políticos,

[...] identificados com a proteção da esfera de integridade física e moral do ser humano, com o objetivo de serem resguardadas as liberdades individuais de ir e vir, pensamento, expressão, reunião e associação, sempre para se privilegiar a perspectiva individual, mesmo quando o exercício do direito de associação ou reunião se estenda a coletividades de pessoas. (PEIXINHO; FERRARO, 2008, p. 6955).

A segunda dimensão dos direitos fundamentais nasce a partir do modo de produção capitalista, dadas as novas configurações de trabalho remunerado. São os direitos sociais, culturais e econômicos, caracterizados pela abrangência das coletividades. Exemplo desses direitos são: "a assistência à saúde e os benefícios oriundos da Previdência Social [...], o direito à associação em sindicatos" (PEIXINHO; FERRARO, 2008, p. 6955). Sobre os 
direitos sociais, Bittar (2014) destaca que emanam do princípio de dignidade humana, e a igualdade é um pilar básico da democracia.

$\mathrm{Na}$ terceira dimensão dos direitos fundamentais estão os direitos difusos ou transindividuais, nos quais o interesse coletivo se sobrepõe ao individual. São caracterizados pela alusão a valores que conduzam à sociedade ao desenvolvimento e ao progresso considerando a proteção e a continuidade do ser humano (da humanidade). Exemplos de direitos da terceira dimensão são: "a fraternidade, a paz, o meio ambiente, o respeito ao patrimônio histórico e cultural, e, ainda, a nova ordem econômica mundial, com valores redefinidos pelo respeito dos países ao pleno desenvolvimento interno" (PEIXINHO; FERRARO, 2008, p. 6956).

Por essa ótica, o conceito de desenvolvimento tratado na terceira geração não se limita à perpetuação da espécie, tampouco aos mínimos sociais necessários para o ser humano (trabalhador) sobreviver. Nesta categoria, precede o exercício estatal de criar mecanismos, políticas sociais, as quais garantam o desenvolvimento pleno da humanidade, indispensáveis para o exercício da cidadania, a continuidade e a promoção das capacidades humanas essenciais à liberdade. Conforme dispõem Peixinho e Ferraro (2008),

[...] Indissociável do direito ao desenvolvimento é o reconhecimento de outros direitos, coadjuvantes do pleno desenvolvimento dos Estados e indivíduos, que são os direitos pertinentes ao exercício da democracia, à informação e ao pluralismo. (PEIXINHO; FERRARO, 2008, p. 6958).

Portanto, a DUDH apresentou à comunidade internacional novos valores pela preservação da humanidade que, para sua concretude, compreendem a aplicabilidade das três diferentes dimensões do direito: individuais, sociais e difusos. Neste rol de direitos inclui-se o direito ao desenvolvimento, configurado na terceira dimensão, o qual apresenta a educação como componente para a construção cidadã. À época, estando em regime militar, o Brasil se tornou tardiamente signatário dos princípios que norteiam a Declaração, validando-os apenas em 1988, na redação da nova Constituição Federal. A redação atribui como fundamento do Estado Democrático de Direito a dignidade humana, e posiciona a educação como dever do Estado.

Outro documento que reitera a educação enquanto demanda do Estado no fomento dos direitos humanos é a Declaração de Viena, de 1993. Em sua redação, os itens 
18, 24, 63 utilizam a educação, entre outras áreas, para proteção de mulheres, crianças, imigrantes e pessoas com deficiência, respectivamente. Já o item 33 atribui à educação o objetivo de "promover a compreensão, a tolerância, a paz, as relações amigáveis entre as nações e todos os grupos raciais ou religiosos" (ONU MULHERES, 1993), apontando a necessidade de incluir os direitos humanos nas políticas educacionais nacionais e internacionais. No item 80, aborda-se a “educação sobre direitos do homem":

A educação sobre direitos do homem deverá incluir a paz, a democracia, o desenvolvimento e a justiça social, conforme definido nos instrumentos internacionais e regionais sobre direitos humanos, por forma a alcançar-se um entendimento comum e a consciência que permitam reforçar o compromisso universal dos direitos humanos (ONU MULHERES, 1993).

Segundo Castilho (2016), a Declaração de Viena ressaltava a educação em direitos humanos, a qual deve ocorrer tanto na educação formal quanto na não formal. A partir da união entre educação e direitos humanos, Rayo (2013) considera que a educação, ao buscar o desenvolvimento integral do sujeito, não pode negar a contribuição dos direitos humanos. Assim, Rayo (2013) destaca que os professores representam um papel importante em uma educação que se importa com os direitos humanos, com a democracia e a paz, pois, são esses profissionais que apresentam aos estudantes as problemáticas sociais e a importância da busca por soluções. Para Castilho (2016), educação e direitos humanos são dimensões que se entrelaçam para garantir e promover a igualdade de oportunidades, o desenvolvimento da pessoa e o exercício da cidadania e, com isso, o fortalecimento da democracia.

De acordo com Cury (2013, p. 1057), “a educação em Direitos Humanos pretende a criação de uma cultura que, junto com outros marcos legais, faça avançar o que a Constituição prevê e também o que demanda a consciência universal contemporânea". Complementando, Candau e Sacavino (2013) discutem que a educação em direitos humanos não tem apenas relação com temáticas no currículo da educação formal, mas também diz respeito a cultura da escola, orientada à mudança social. Destacam, na educação em direitos humanos, a relevância de desenvolver processos para orientar a formação dos sujeitos, principalmente de grupos sociais discriminados. Também afirmam a importância de compreender qual o objetivo se pretende atingir com a educação em direitos humanos e, com isso, buscar estratégias metodológicas que garantam a 
participação dos sujeitos no processo, afinal, para as autoras, educar em direitos humanos significa assegurar participação em experiências nas quais se consiga vivenciá-los.

Candau (2012) afirma que a educação em direitos humanos é o objeto de diversos debates, alguns voltados à igualdade, e outros à discussão entre igualdade e diferença. É muito importante também destacar o ponto de vista da autora quando afirma que igualdade, porvezes, é confundida com homogeneização. Todavia, desde a década de 90, essa realidade se transforma em resposta aos movimentos sociais existentes e, com isso, na educação, programas e políticas se voltam ao reconhecimento da diversidade na escola.

Nota-se que Candau (2012) relaciona a educação em direitos humanos ao direito a educação, como parte integrante, e como elemento importante na qualidade da educação. Essas questões se relacionam a uma educação que se compromete a educar estudantes que possuem direitos, a afirmar à democracia, à justiça, e reconhecer a diversidade. Cury (2013) menciona a necessidade de uma educação de qualidade — sendo essa urgência por qualidade uma demanda social —, alicerçada nos direitos humanos e na cidadania. Candau (2012) problematiza que, na elaboração de uma cultura que considere os direitos humanos, essas questões se consolidam no plano teórico, mas ainda são muito frágeis, na prática, a exemplo da formação de professores, das práticas pedagógicas, ou das políticas públicas.

Isto posto, a partir do referencial teórico, pode-se observar que alguns autores relacionam educação e direitos humanos a questões ligadas à dignidade das pessoas, à cidadania, à democracia, a uma nova cultura, e, inclusive, à educação em direitos humanos. Para Castilho (2016, p. 183), "educação leva, quase automaticamente, à democracia, porque incentiva a cidadania. Portanto, educação é questão política”. Como afirma Rayo (2013, p. 114): "tratar os direitos humanos como elemento básico da educação da cidadania e para a democracia significa considerar uma política educacional que afete tanto o programa curricular como as estruturas organizativas".

\section{Metodologia}

Esta pesquisa se caracteriza por uma abordagem qualitativa e, quanto aos procedimentos, por análise documental. A análise documental, segundo Ludke e André (1986), consiste em uma técnica de abordagens de dados qualitativos, a qual busca novos aspectos de um tema ou problema, ou complementar informações obtidas com outras 
técnicas. De acordo com Ludke e André (1986), a análise documental é fonte natural de informação, surge em determinado contexto e fornece informações acerca dele. Podem ser considerados documentos: normas, leis, cartas, regulamentos, jornais, arquivos escolares, diários pessoais, dentre outros.

A pesquisa documental partiu das Diretrizes Curriculares Nacionais e da Base Nacional Comum Curricular, por se tratarem de documentos que orientam às políticas curriculares nacionais. Isto posto, buscou-se identificar nos documentos as relações estabelecidas entre educação e direitos humanos, e compreender às significações sobre direitos humanos nesses documentos. Portanto, mediante os objetivos propostos no artigo, elencaram-se duas categorias de análise nas DCNs e na BNCC: (1) Como os direitos humanos são apresentados nos documentos e (2) quais as relações entre direitos humanos e educação.

\section{As Diretrizes Curriculares Nacionais (2013) e a Base Nacional Comum Curricular (2017)}

As Diretrizes Curriculares Nacionais apresentam orientações acerca da "[...] organização, articulação, o desenvolvimento e a avaliação das propostas pedagógicas de todas as redes de ensino brasileiras" (BRASIL, 2013, p. 4). Construída a partir de ampla participação social, as DCNs são normas específicas para a Educação Básica, e orientam o planejamento do currículo. Logo, são um conjunto de definições, princípios e fundamentos norteadores da organização, da articulação, do desenvolvimento e da avaliação das propostas pedagógicas da escola (ROSSI, 2016). As diretrizes possuem caráter de obrigatoriedade, objetivam guiar o planejamento curricular dos sistemas de ensino e da escola, fundamentando o currículo e os conteúdos mínimos.

Transformações no cenário político brasileiro na segunda década dos anos 2000, a partir do impeachment da Presidente Dilma Rousseff, em 2016, marcam uma série de retrocessos no que diz respeito às políticas sociais (AGUIAR; DOURADO, 2018). No tocante às políticas educacionais, ações de caráter conservador e privatista tornam-se pauta de discussões sobre financiamento, avaliação, currículo e formação docente: 


\begin{abstract}
buscarem efetivar o PNE (2014-2024), por meio de articulação federativa, da institucionalização do Sistema Nacional de Educação e do redimensionamento e articulação do papel do Estado, visando a garantir o direito à educação, passaram a redirecionar estas proposições por intermédio de políticas de regulação sob o viés privatista (DOURADO; OLIVEIRA, 2018, p. 40).
\end{abstract}

Em 2017, publica-se a Base Nacional Comum Curricular, a qual orienta a organização curricular da educação nacional. Embora o documento não anule às DCNs, sua centralidade gera uma série de controversas, tanto no que diz respeito à organização dos currículos, como nas políticas de formação docente (AGUIAR; DOURADO, 2018; ANPED, 2019). Neira, Alviano Júnior e Almeida (2016) afirmam que a primeira versão da BNCC diz respeito a um ponto de partida, não a um currículo mínimo, com intuito de apoiar propostas existentes. A segunda versão do documento trouxe um rol de objetivos de aprendizagens para garantir vários direitos de aprendizagens e desenvolvimento. A existência deste documento é uma exigência constitucional. A terceira versão,

[...] produzida pelo Ministério da Educação (MEC) e na versão aprovada pelo CNE, por meio da Resolução CNE/CP n² 2, de 22 de dezembro de 2017 (BRASIL, 2017a), foi reforçada a lógica de uma aprendizagem com base em competências, com concepção curricular restritiva e fortemente articulada a avaliação de tipo padronizada e estandardizada (DOURADO; OLIVEIRA, 2018, p. 40).

Diante da disparidade ideológica dos contextos de produção das DCNs e da BNCC, cabe analisar de que maneira as relações entre direitos humanos e educação aparecem nesses documentos. Uma rápida busca pelo termo “direitos humanos" já oferece algumas pistas sobre como tais conceitos se articulam: enquanto nas DCNs o termo é citado 316 vezes em suas 565 páginas, na BNCC, aparece apenas 64 vezes em 600 páginas. Sendo assim, convém perguntar acerca dos modos como os direitos humanos aparecem em cada um dos documentos.

Nas DCNs, os direitos humanos são referidos logo no início do documento em relação aos compromissos educacionais, tais como: construir uma sociedade justa, solidária; reduzir desigualdades; promover o bem de todos sem discriminação; defesa da paz; repúdio ao preconceito; prevalência dos direitos humanos, dentre outros (BRASIL, 2013). Também, quando indicados os requisitos da escola com qualidade social, mencionase o respeito aos direitos humanos. Além disso, os direitos humanos são citados em relação 
à necessidade de conceber uma cultura de direitos humanos, e formar, com isto, cidadãos plenos.

Em relação à educação infantil, as diretrizes pontuam na organização curricular que as crianças fazem parte de um mundo de direitos humanos. Por isto, possuem, além dos direitos considerados fundamentais, a participação e a liberdade de expressão. No ensino fundamental, aponta-se o direito à educação como fundamento das diretrizes. Nesse capítulo, são apresentados os direitos civis, políticos e sociais, os quais são universais; menciona-se também a Declaração Universal dos Direitos Humanos, que afirma o pleno desenvolvimento da pessoa e o respeito aos direitos humanos como objetivos da educação. As diretrizes afirmam que, para construir uma sociedade mais democrática, fazse necessário contemplar elementos curriculares sobre direitos humanos.

Para o ensino médio, os direitos humanos são mencionados como princípio. No Projeto Político Pedagógico (PPP) devem estar contemplados a valorização e a promoção dos direitos humanos, em temas como gênero, etnia, raça, orientação sexual, religião, pessoas com deficiência; e práticas que contribuam para enfrentamento de preconceitos, violências e discriminações. Inclusive, reporta-se que direitos humanos devem permear o currículo do ensino médio, para promover o respeito aos direitos e à convivência humana. Além disso, sobre a educação de jovens e adultos em situação de privação de liberdade, as DCNs evidenciam a necessidade de abordagem de temas como direitos humanos e combate ao racismo, sexismo, intolerância religiosa, homofobia, entre outros, contribuindo para alcançar a mudança cultural.

No capítulo das Diretrizes Nacionais para a Educação em Direitos Humanos, presente nas DCNs, os direitos humanos são estabelecidos como efeito da luta por universalização e reconhecimento da dignidade humana. Segundo o documento, após as atrocidades e impactos da Primeira e da Segunda Guerras Mundiais, em 1945, foi criada a ONU, como organismo da ordem internacional; em 1948, elaborou-se a DUDH, para afirmar a universalidade dos direitos, aplicáveis internacionalmente a todos os seres humanos. Ressalta-se que os anos 1960-1970 foram um período de retrocesso em relação a esses direitos, devido à ditadura militar, mesmo que o Brasil tenha se tornado signatário dos direitos humanos em 1966. Na contemporaneidade, continuam os desafios e lutas enfrentados para promoção dos direitos humanos. 
As DCNs afirmam que os direitos humanos “[...] dizem respeito a um processo em constante elaboração, ampliando o reconhecimento de direitos face às transformações ocorridas nos diferentes contextos sociais, históricos e políticos" (BRASIL, 2013, p. 515). Neste sentido, conforme as Diretrizes Curriculares Nacionais, os direitos humanos estão relacionados aos "[...] direitos civis, políticos, sociais, econômicos, culturais e ambientais, sejam eles individuais, coletivos, transindividuais ou difusos, que se referem à necessidade de igualdade e de defesa da dignidade humana" (BRASIL, 2013, p. 516). Os direitos humanos aparecem no documento como forma de luta contra desigualdades e discriminações praticadas contra as diversidades étnicas, até de identidade de gênero, raça, orientação sexual, bem como opressões relacionadas a detenção do poder (por minorias sociais).

Ao evidenciar o respeito para conceber uma sociedade que valorize condições para a garantia da dignidade, o documento salienta violações dos direitos no Brasil, como a pobreza, as discriminações e os autoritarismos. Essas formas de violações dos direitos humanos em nossa sociedade são consequências das desigualdades de todo o tipo, como a econômica, a política, a cultural e a social, e se manifestam nos espaços educacionais. Diante disto, as DCNs reafirmam o papel dos profissionais da educação para a reversão do quadro de violações históricas aos direitos humanos.

A educação é evidenciada no documento como mediação para acesso ao legado dos direitos humanos, logo, é interpretada como direito humano. Assim, os direitos humanos estão presentes no currículo da educação infantil, do ensino fundamental, do ensino médio, e da educação de jovens e adultos em situação de privação de liberdade. Conforme o documento, temáticas relacionadas aos direitos humanos devem estar contempladas também na educação indígena, na educação especial, na quilombola e na de jovens e adultos.

A escola assume um lugar importante na garantia dos direitos humanos, responsável por criar espaços que promovem a cultura dos direitos humanos em diversas modalidades e níveis de ensino. O ambiente educacional que concebe, na prática, os direitos humanos, segundo o documento, respeita diferenças e garante práticas democráticas. Por isto, as Diretrizes Curriculares Nacionais definem que, no ambiente escolar, deve haver práticas de promoção dos direitos humanos em diversos momentos: “[...] na elaboração do projeto político pedagógico, na organização curricular, no modelo 
de gestão e avaliação, na produção de materiais didático-pedagógicos, quanto na formação inicial e continuada dos/as profissionais da educação" (BRASIL, 2013, p. 521).

As DCNs afirmam que a educação em direitos humanos se fortaleceu nos últimos anos, através do reconhecimento das relações entre educação e direitos humanos. Descreve-se no documento a necessidade de construir práticas em que direitos humanos sejam contemplados na educação, bem como seus processos de promoção e defesa.

Neste sentido, a educação em direitos humanos busca formar integralmente estudantes ativos na vida democrática, os quais exercitam seus direitos e suas responsabilidades. A educação em direitos humanos, segundo as diretrizes, deve ser contemplada no currículo, além da educação básica, na educação superior, de diferentes formas, seja pela transversalidade (através de temas dos direitos humanos), seja por meio do conteúdo específico de uma disciplina, ou de maneira mista.

Na Base Nacional Comum Curricular, não se apresenta um conceito de direitos humanos, mas se afirma o compromisso da escola com uma formação integral, pautada nos direitos humanos e em princípios democráticos. Assim, os direitos humanos aparecem no documento, em primeiro lugar, nas competências esperadas da educação básica:

7. Argumentar com base em fatos, dados e informações confiáveis, para formular, negociar e defender ideias, pontos de vistas e decisões comuns que respeitem e promovam os direitos humanos, a consciência socioambiental e o consumo responsável em âmbito local, regional e global, com posicionamento ético em relação cuidado de si mesmo, dos outros e do planeta. (BRASIL, 2017, p. 9).

Os direitos humanos também se manifestam nas competências do ensino fundamental. Primeiro, nas relacionadas a linguagens, em que o estudante deve utilizá-las para defender pontos de vista que promovam os direitos humanos e o respeito ao outro. No campo da língua portuguesa, segundo o documento, o tema dos direitos humanos perpassa debates e organização de modos de defesa desses direitos; nas competências, o estudante deve analisar informações, a partir de diversas interações sociais e mídias, que ferem os direitos humanos. "Trata-se de promover uma consciência de direitos, uma valorização dos direitos humanos e a formação de uma ética da responsabilidade (o outro tem direito a uma vida digna tanto quanto eu tenho)" (BRASIL, 2017, p. 137). Quanto as habilidades de Língua Portuguesa, menciona-se a capacidade de compreensão do cenário 
de promulgação dos direitos, de políticas e de leis, com intuito de possibilitar a vivência democrática.

$\mathrm{Na}$ área de Ciências Humanas do ensino fundamental é dito que se espera conceber uma formação ética e, com isto, valorizar os direitos humanos: respeito ao ambiente, à coletividade, a valores como participação e solidariedade; nas competências, compreender a si e ao outro como diferentes identidades, respeitosamente; construir argumentos, defender ideias que promovam os direitos humanos. Nas habilidades da disciplina de história, o estudante deve associar cidadania aos princípios de respeito com a diversidade e os direitos humanos. Espera-se também que o estudante relacione a Carta dos Direitos Humanos com a defesa da dignidade, e ao processo de afirmação dos direitos considerados fundamentais. Ademais, deve valorizar instituições que defendam esses direitos e identifiquem agentes violadores; saber identificar questões da ditadura militar no Brasil e possíveis violações dos direitos.

$\mathrm{Na}$ área do ensino religioso do ensino fundamental é citado como um dos objetivos proporcionar conhecimentos sobre o direito à diversidade de crenças, atrelado à promoção dos direitos humanos. Nas competências, é referida a problematização e o debate acerca de discursos que representem intolerância religiosa, a fim de assegurar os direitos humanos na cidadania, e em uma cultura de paz.

No ensino médio são descritas nas competências de Linguagens e Tecnologias a compreensão de processos identitários e relações de poder; a capacidade de exercitar o diálogo, de resolver conflitos a partir de princípios e valores associados à democracia, igualdade e aos direitos humanos; o uso de diferentes linguagens na promoção dos direitos humanos. Em relação às habilidades, menciona-se o diálogo a partir de diversas linguagens, baseado em valores e princípios dos direitos humanos, assim como a capacidade de formular propostas que os considerem.

Na área de Ciências Humanas e Sociais Aplicadas (Filosofia, Geografia, Sociologia e História) do ensino médio, alude-se ao respeito aos direitos humanos. Nas competências das Ciências Humanas e Sociais Aplicadas se faz referência à identificação e ao combate de violações e preconceitos, pela adoção de princípios democráticos, éticos e inclusivos, em apreço aos direitos humanos; nas habilidades, sugere-se verificar os impactos das diversas transformações tecnológicas, e promover possíveis ações para superar violações dos direitos humanos, como também desigualdades sociais. 
No entanto, apesar de os direitos humanos estarem pautados na BNCC (BRASIL, 2017), nas habilidades e competências no ensino (em diversas disciplinas no ensino fundamental e no médio), nota-se a ausência do conceito de direitos humanos nesse documento, de sua problematização e do comprometimento diante das violações aos direitos humanos que assolam a sociedade brasileira, diferente das Diretrizes Curriculares Nacionais. Além disso, apesar de não conceituar educação em direitos humanos, a BNCC diz ser dever dos sistemas de ensino incorporar aos currículos e às propostas pedagógicas diversos temas (como educação ambiental, história, cultura afro-brasileira, etc.), entre eles a educação em direitos humanos.

\section{A educação em e para os direitos humanos nos documentos educacionais}

A partir dos documentos analisados, percebe-se que direitos humanos e educação estão conectados. Em primeiro lugar, as Diretrizes Curriculares Nacionais reconhecem a educação como direito, “[...] como uma das mediações fundamentais tanto para o acesso ao legado histórico dos Direitos Humanos, quanto para a compreensão de que a cultura dos Direitos Humanos é um dos alicerces para a mudança social” (BRASIL, 2013, p. 515). Identifica-se a importância da educação na promoção dos direitos humanos, assim como a relação entre ambos concebida a partir da necessidade de mudança cultural.

Em um cenário de violações, as DCNs trazem a necessidade de uma educação em direitos humanos para "[...] influenciar na construção e na consolidação da democracia como um processo para o fortalecimento de comunidades e grupos tradicionalmente excluídos dos seus direitos" (BRASIL, 2013, p. 516). Assim sendo, com a educação em direitos humanos apresentada no documento, outras relações entre educação e direitos humanos são observadas:

Como a Educação em Direitos Humanos requer a construção de concepções e práticas que compõem os Direitos Humanos e seus processos de promoção, proteção, defesa e aplicação na vida cotidiana, ela se destina a formar crianças, jovens e adultos para participar ativamente da vida democrática e exercitar seus direitos e responsabilidades na sociedade, também respeitando e promovendo os direitos das demais pessoas. É uma educação integral que visa o respeito mútuo, pelo outro e pelas diferentes culturas e tradições. (BRASIL, 2013, p. 516). 
Desse modo, as Diretrizes Curriculares Nacionais (BRASIL, 2013, p. 516) afirmam: “reconhecer e realizar a educação como direito humano e a Educação em Direitos Humanos como um dos eixos fundamentais do direito à educação, exige posicionamentos claros quanto à promoção de uma cultura de direitos". Nota-se que as diretrizes articulam a educação como direito humano, e em direitos humanos. A educação é interpretada como um dos direitos humanos, e a educação em direitos humanos está inserida nesse conjunto.

Nas DCNs, “[...] o direito à educação é concebido como direito inalienável de todos/as os/as cidadãos/ãs e condição primeira para o exercício pleno dos Direitos Humanos" (BRASIL, 2013, p. 520). Desta maneira, espera-se, na educação básica, a formação para a cidadania, oferecendo condições para desenvolvimento integral dos estudantes. A cidadania também aparece nas relações entre direitos humanos e educação. Nas DCNs, a missão essencial da escola é conceber uma cultura de direitos humanos que prepare cidadãos, “a Educação Básica é direito universal e alicerce indispensável para a capacidade de exercer em plenitude o direito à cidadania" (BRASIL, 2013, p. 17).

A Base Nacional Comum Curricular aponta, nas habilidades de história do ensino fundamental, que o estudante deve associar noções de cidadania a princípios de respeito à diversidade e aos direitos humanos. Observa-se também, em ambos os documentos, relações entre direitos humanos, educação e democracia. A propósito, as DCNs asseveram:

Compreender a relação indissociável entre democracia e respeito aos direitos humanos implica no compromisso do Estado brasileiro, no campo cultural e educacional, de prover seu aprendizado em todos os níveis e modalidades de ensino. (BRASIL, 2013, p. 165).

Em vista disso, a DCN evidencia que, em um contexto democrático, deve-se propiciar espaços nos quais a cultura de direitos humanos esteja presente em todas as práticas do ambiente escolar, como no currículo, no PPP, nas formações inicial e continuada dos professores, nos materiais didático-pedagógicos, e no modelo de gestão. A Base Nacional Comum Curricular traz, nas competências e habilidades, práticas que envolvem os direitos humanos e democracia, afirmam o compromisso da escola em propiciar uma formação pautada pelos direitos humanos. Entretanto, não discute a relação entre tais competências e a Educação em Direitos propriamente dita, tal como propõem as DCNs e o Plano Nacional de Educação em Direitos Humanos (BRASIL, 2007). 
São observadas outras articulações entre direitos humanos e educação, como o desenvolvimento de práticas que contribuam para a promoção dos direitos humanos no espaço escolar, são indicadas nas Diretrizes Curriculares Nacionais (BRASIL, 2013, p. 521): “[...] elaboração do projeto político pedagógico, na organização curricular, no modelo de gestão e avaliação, na produção de materiais didático-pedagógicos, quanto na formação inicial e continuada dos/as profissionais da educação".

Segundo as DCNs, as escolas e os profissionais da educação desempenham um papel importante na criação de espaços - em diferentes modalidades e etapas de ensino - que promovam os direitos humanos. Evidenciam como é importante que os sujeitos do campo educacional se unam na luta pela valorização dos direitos humanos, e no desafio de efetivar/conceber uma educação em direitos humanos. Destarte, o ambiente educacional é evidenciado como espaço de defesa dos direitos humanos, o qual busca promovê-los e considera a necessidade do respeito às diferenças, de maneira que sejam garantidas práticas democráticas (livres de violências e outras formas de violações da dignidade).

\section{À guisa de discussão}

Na análise de dados se evidencia que as Diretrizes Curriculares Nacionais (BRASIL, 2013) apontam os direitos humanos como resultado da luta pelo reconhecimento e pela universalização da dignidade humana, e que os direitos humanos são histórica e socialmente construídos. Por este motivo, para Rayo (2013), os direitos humanos são elementos essenciais de uma cidadania. Semelhantemente, Scarano (2018) afirma que os direitos humanos garantem liberdade, saúde, dignidade, respeito, ou seja, garantem a vida na totalidade.

Nas Diretrizes Curriculares Nacionais, o conceito de direitos humanos perpassa todo o documento, mostra-se presente em questões ligadas ao currículo e às aprendizagens, e destaca como é vital uma educação pautada nos direitos humanos.

Na Base Nacional Comum Curricular, os direitos humanos não aparecem descritos em conceitos, mas ganham espaço nas habilidades e competências da educação básica, posto que o documento se organiza em uma perspectiva de competências. Educação em direitos humanos aparece nas abordagens necessárias no currículo, mas pouco se articula tal necessidade aos pressupostos que a orientam, em termos históricos, sociais e teóricos. 
Nas DCNs, a educação como direito é abordada tanto na perspectiva da formação para cidadania, da formação de sujeitos de direitos, quanto na perspectiva da igualdade. Os autores Botelho e Schwarcz (2012) trazem o conceito de cidadania como uma identidade social politizada, ou seja, a cidadania é uma noção construída coletivamente, ganhando sentido nas experiências sociais e individuais, como identidade social. A perspectiva de igualdade, no que lhe concerne, constrói-se em contraposição à noção de homogeneização ou à lógica liberal das relações entre diferença e identidade (SILVA, 2000; CANDAU, 2012), o que se percebe pela criação, desde a década de 1990, segundo Candau (2012), de políticas, iniciativas e programas voltados ao reconhecimento das diferenças no currículo, tais como: história e a cultura afro-brasileira, indígena, africana nos currículos, trazida pela lei 10.639/2003; a perspectiva da escola inclusiva, conforme discorre o Capítulo V da LDB (Lei 9.394/96); materiais pedagógicos voltados ao combate da homofobia, do racismo, do sexismo, apresentados pelo Projeto Educação do Reconhecimento da Diversidade Sexual e Enfrentamento ao sexismo e a homofobia, a partir da Resolução 16/2009, do FNDE (CANDAU, 2012). Nesse processo, Candau (2012) assevera que se faz necessária a educação em direitos humanos, voltados para afirmar e construir uma cultura de direitos humanos na escola e em sociedade.

A democracia e a cidadania também foram questões que apareceram nas relações entre educação e direitos humanos nos documentos. O PNEDH (BRASIL, 2007) afirma que uma concepção de direitos humanos contemporânea abrange conceitos de cidadania ativa e cidadania democrática, inspirados em princípios de liberdade, igualdade, equidade e diversidade. O exercício da cidadania necessita da formação de cidadãos que considerem tanto seus direitos, quanto seus deveres, em uma formação de sujeitos de direitos.

\footnotetext{
A democracia, entendida como regime alicerçado na soberania popular, na justiça social e no respeito integral aos direitos humanos, é fundamental para o reconhecimento, a ampliação e a concretização dos direitos. Para o exercício da cidadania democrática, a educação, como direito de todos e dever do Estado e da família, requer a formação dos(as) cidadãos(ãs) (BRASIL, 2007, p. 24).
}

Para Rayo (2013, p. 164), “[...] a educação baseada em valores democráticos é um requisito para o exercício dos direitos humanos”. No PNEDH (BRASIL, 2007), a educação tem intenção de efetivar uma cidadania plena, e contribui ao assegurar que todos tenham acesso à participação efetiva. Neste sentido, a educação em direitos humanos também se 
destaca, ao buscar ações pedagógicas conscientizadoras, voltada ao respeito e pautadas na valorização das diversidades e da formação da cidadania ativa (BRASIL, 2007).

Articulações entre direitos humanos e educação também apareceram na análise de dados a respeito da necessidade de conteúdos relacionados aos direitos humanos no ambiente escolar, em diversos aspectos: no currículo, no projeto político pedagógico, no modelo de gestão e avaliação, nos materiais didáticos e na formação dos professores. Isto o PNEDH (BRASIL, 2007) também o afirma, porém, relacionado à educação em direitos humanos, como eixo da educação básica, na composição do currículo, na formação inicial e continuada dos professores, no PPP, nos materiais didáticos, no modelo de gestão e na avaliação. Nesta lógica, Barrios, Salgado e Miranda (2021) alegam, a partir das diretrizes, que, no currículo, os conteúdos acerca dos direitos humanos devem ser trabalhados por meio de diferentes linguagens, como a teatral, a literária, a musical, a corporal, dentre outras; afirmam ainda que, apesar de haver direcionamentos nos documentos (nacional e internacionalmente) acerca da educação em direitos humanos, ainda se está muito distante deles nas práticas pedagógicas, no PPP e nos currículos de boa parte das escolas brasileiras.

\section{CONSIDERAÇÕES FINAIS}

Este artigo, ao buscar suscitar reflexões relacionadas aos direitos humanos e a educação, ao evocar uma concepção relevante de educação em e para direitos humanos, analisou às Diretrizes Curriculares Nacionais e à Base Nacional Comum Curricular, e sua abordagem da temática dos direitos humanos.

A partir do referencial teórico apresentado e da análise dos documentos educacionais, nota-se a ênfase na relação entre direitos humanos e educação. Com isto, evidencia-se que educação e direitos humanos caminham juntos. Revela-se a necessidade de uma educação baseada no respeito (a pessoas, culturas e crenças diferentes), na igualdade, na dignidade humana, na democracia, na cidadania, na justiça, na mudança cultural, enfim, em uma educação nos direitos humanos, para uma cultura dos direitos humanos; essas imbricações estão presentes no currículo escolar e na formação de professores, pois, ambos precisam trabalhar temáticas relacionadas aos direitos humanos. 
Além disso, alguns autores apontam a figura do professor como essencial na consolidação de uma educação e uma cultura em direitos humanos.

Cabe ainda ressaltar que, diante dos contextos de produção dos documentos, as relações entre direitos humanos e educação surgem de formas distintas. Nas DCNs é evidente o comprometimento social da educação para a defesa, promoção e proteção dos direitos humanos. A BNCC, por sua vez, ao ser construída a partir de uma "pedagogia das competências", parece reduzir o papel social da educação, tornando os direitos humanos e a EDH mera formalidade ou conteúdo a ser inserido nos documentos, nas políticas e nas pedagogias locais.

A relação entre educação e direitos Humanos é essencial, porquanto sua imbricação faz compreender a realidade sociopolítica em que os indivíduos estão imersos. Ora, transcender o mundo, às manifestações ordinárias e cerceadoras de direitos, é submergir na ignorância para superá-la. A educação tem o papel de nortear o ser humano para enxergar sua realidade, como sujeito e não objeto (FREIRE, 2018).

A efetivação ou, como diria Comparato (2019), a afirmação dos direitos humanos vai além de um simples substrato jurídico e político. Significa o estabelecimento de um modus raciocinandi no qual se reconhece o ser humano de maneira integral. A integralidade humana é a base da dignidade da pessoa, que fora há muitos séculos rechaçada e até precificada. A compreensão desse cenário advém de uma conscientização crítica, pois, sem que o indivíduo se torne consciente de sua realidade, é muito difícil que atue para mudá-la (FREIRE, 2018).

A saída do fatalismo social - que desumaniza e pode condicionar à realidade — pode ocorrer pela educação. No entanto, Freire (2018), ao comentar sobre a instrumentalização da educação, afirma que "nenhuma ação educativa pode prescindir de uma reflexão sobre o homem e de uma análise sobre suas condições culturais" (FREIRE, 2018, p. 82). Isto significa que, para a educação promover uma transgressão ontológica acerca da realidade, precisa incluir no cerne da questão o indivíduo, e promover-lhe condições de saída da condição de mero espectador, para a de protagonista. 


\section{REFERÊNCIAS}

AGUIAR, Márcia Angela da S.; DOURADO, Luiz Fernandes (orgs.). A BNCC na contramão do PNE 2014-2024: avaliação e perspectivas. Recife: ANPAE, 2018. Disponível em: https://www.seminariosregionaisanpae.net.br/BibliotecaVirtual/4-Publicacoes/BNCCVERSAO-FINAL.pdf. Acesso em: $1^{\circ}$ jun. 2021.

ANPED. Uma formação formatada. [Rio de Janeiro]: Associação Nacional de PósGraduação e Pesquisa em Educação, 2019. Disponível em: https://anped.org.br/sites/default/files/images/posicao_da_anped_sobre_o_texto_refere ncia_-

_diretrizes_curriculares_nacionais_e_base_nacional_comum_para_a_formacao_inicial_e _continuada_de_professores_da_educ.pdf. Acesso em: $1^{\circ}$ jun. 2021.

BARRIOS, Alia; SALGADO, Giulia Ribeiro; MIRANDA, Natália Nascimento. Educação em Direitos Humanos no Ensino Fundamental: práticas pedagógicas e concepções de professores. Revista Atos de Pesquisa em Educação, Blumenau, v. 16, e8471, 2021. DOI http://dx.doi.org/10.7867/1809-0354202116e8471. Disponível em: https://proxy.furb.br/ojs/index.php/atosdepesquisa/article/view/8471/4953. Acesso em: 12 mai. 2021.

BENEVIDES, Maria Victoria. Educação em Direitos Humanos: de que se trata? Programa Ética e Cidadania, construindo valores na escola e na sociedade. MEC/SEB: 2007. Disponível em: http://portal.mec.gov.br/seb/arquivos/pdf/Etica/9_benevides.pdf. Acesso em: $1^{\circ}$ jun. 2021.

BITTAR, Carla Bianca. Educação e direitos humanos no Brasil. São Paulo: Saraiva, 2014. Ebook.

BOTELHO, André; SCHWARCZ, Lilia Moritz. Cidadania, um projeto em construção: minorias, justiça e direitos. 1. ed. São Paulo: Claro Enigma, 2012. 
BRASIL. Comitê Nacional de Educação em Direitos Humanos. Plano Nacional de Educação em Direitos Humanos. Brasília: Secretaria Especial dos Direitos Humanos, Ministério da Educação, Ministério da Justiça, UNESCO, 2007. Disponível em: http://portal.mec.gov.br/docman/2191-plano-nacional-pdf/file. Acesso em: $1^{\circ}$ jun. 2021.

BRASIL. [Constituição (1988)]. Constituição da República Federativa do Brasil de 1988. Brasília, DF: Presidência da República, [2021]. Disponível em: http://www.planalto.gov.br/ccivil_03/constituicao/constituicao.htm. Acesso em: $1^{\circ}$ jun. 2021.

BRASIL. Ministério da Educação. Base Nacional Comum Curricular. Brasília: MEC, 2017. Disponível em: http://basenacionalcomum.mec.gov.br/images/BNCC_El_EF_110518_versaofinal_site.pdf. Acesso em: $1^{\circ}$ jun. 2021.

BRASIL. Ministério da Educação. Diretrizes Curriculares Nacionais Gerais da Educação Básica. Brasília: MEC, SEB, DICEI, 2013. Disponível em: http://portal.mec.gov.br/index.php?option=com_docman\&view=download\&alias=15548d-c-n-educacao-basica-nova-pdf\&ltemid=30192. Acesso em: $1^{\circ}$ jun. 2021.

CANDAU, Vera Maria Ferrão. Direito à educação, diversidade e educação em Direitos Humanos. Educ. Soc., Campinas, v. 33, n. 120, p. 715-726, jul./set, 2012. DOI https://doi.org/10.1590/S0101-73302012000300004. Disponível em: https://www.scielo.br/scielo.php?pid=S010173302012000300004\&script=sci_abstract\&tlng=fr. Acesso em: $1^{\circ}$ jun. 2021.

CANDAU, Vera Maria Ferrão et al. Educação em direitos humanos e formação de professores(as). 1. ed. São Paulo: Cortez, 2014. E-book.

CANDAU, Vera Maria Ferrão; SACAVINO, Susana Beatriz. Educação em Direitos Humanos e formação de educadores. Educação, Porto Alegre, v. 36, n. 1, p. 59-66, jan./abr. 2013. Disponível 
https://revistaseletronicas.pucrs.br/ojs/index.php/faced/article/view/12319/8741. Acesso em: $1^{\circ}$ jun. 2021.

CASTILHO, Ricardo. Educação e direitos humanos. São Paulo: Saraiva, 2016.

COMPARATO, F. K. A afirmação histórica dos direitos humanos. 12. ed. São Paulo: Saraiva Educação, 2019. E-book.

CURY, Carlos Roberto Jamil. Políticas inclusivas e compensatórias na educação básica. Cadernos de Pesquisa, São Paulo, v. 35, n. 124, p. 11-32, jan./abr., 2005. DOI https://doi.org/10.1590/S0100-15742005000100002. Disponível em: https://www.scielo.br/scielo.php?pid=s0100-15742005000100002\&script=sci_arttext. Acesso em: $1^{\circ}$ jun. 2021.

CURY, Carlos Roberto Jamil. Sentidos da educação na Constituição Federal de 1988. RBPAE, Porto Alegre, v. 29, n. 2, p. 195-206, mai./ago. 2013. Disponível em: https://www.seer.ufrgs.br/rbpae/article/viewFile/43518/27389. Acesso em: $1^{\circ}$ jun. 2021.

DOURADO, Luiz Fernandes; OLIVEIRA, João Ferreira de. Base Nacional Comum Curricular (BNCC) e os impactos nas políticas de regulação e avaliação da educação superior. In: AGUIAR, Márcia Angela da S.; DOURADO, Luiz Fernandes (orgs.). A BNCC na contramão do PNE 2014-2024: avaliação e perspectivas. Recife: ANPAE, 2018. Disponível em: https://www.seminariosregionaisanpae.net.br/BibliotecaVirtual/4-Publicacoes/BNCCVERSAO-FINAL.pdf. Acesso em: $1^{\circ}$ jun. 2021.

FERNANDES, Angela V. M.; PALUDETO, Melina Casari. Educação e Direitos Humanos: desafios para a escola contemporânea. Cad. Cedes, Campinas, v. 30, n. 81, p. 233-249, mai./ago. 2010. Disponível em: https://www.scielo.br/pdf/ccedes/v30n81/a08v3081.pdf. Acesso em: $1^{\circ}$ jun. 2021.

FREIRE, P. Educação e mudança. 39. ed. Rio de Janeiro: São Paulo: Paz e Terra, 2018. 
LÜDKE, Menga; ANDRÉ, Marli Eliza Dalmazo Afonso de. Pesquisa em educação: abordagens qualitativas. São Paulo: E.P.U, 1986. v. 7. 99 p.

NEIRA, Marcos Garcia; ALVIANO JÚNIOR, Wilson; ALMEIDA, Déberson Ferreira de. A primeira e segunda versões da BNCC: Construção, intenções e condicionantes. EccoS - Rev. Cient., São Paulo, n. 41, p. 31-44, set./dez. 2016. Disponível em: https://periodicos.uninove.br/eccos/article/view/6807/3374. Acesso em: $1^{0}$ jun. 2021.

ONU. Declaração Universal dos Direitos Humanos. Paris, 1948. Disponível em: https://nacoesunidas.org/wp-content/uploads/2018/10/DUDH.pdf. Acesso em: $1^{\circ}$ jun. 2021.

ONU MULHERES. Declaração e Programa de Ação de Viena. Viena, 1993. Disponível em: https://www.onumulheres.org.br/wp-content/uploads/2013/03/declaracao_viena.pdf. Acesso em: $1^{\circ}$ jun. 2021.

PEIXINHO, Manoel Messias; FERRARO, Suzani Andrade. Direito ao Desenvolvimento como Direito Fundamental. In: FOLMANN, Melissa; FERRARO, Suzani Andrade (orgs.). Previdência nos 60 anos da Declaração de Direitos Humanos e nos 20 da Constituição Brasileira. Curitiba: Juruá Editora, 2008.

PIOVESAN, F. Direitos humanos e o direito constitucional internacional. 18. ed. São Paulo: Saraiva Educação, 2018. E-book.

RAMOS, Aura Helena. Educação em Direitos humanos: local da diferença. Revista Brasileira de Educação, Rio Janeiro, v. 16, n. 46, jan./abr. 2011. Disponível em: https://www.scielo.br/pdf/rbedu/v16n46/v16n46a11.pdf. Acesso em: $1^{0}$ jun. 2021.

RAYO, José Tuvilla. Educação em direitos humanos: rumo a uma perspectiva global. 2. ed. Porto Alegre: ArtMed, 2013. E-book.

RODRIGUEZ, Maria Elena. Direitos econômicos, sociais e culturais: uma realidade inadiável. Revista Trimestral de Debate da FASE, Rio de Janeiro, ano 31, n. 92, mar./mai. 2002. 
Disponível em: https://fase.org.br/wp-content/uploads/2016/07/Proposta-RevistaTrimestral-de-Debate-da-Fase-n\%C2\%BA-92-2002-05.pdf. Acesso em: $1^{0}$ jun. 2021.

ROSSI, Alexandre José. As políticas de diversidade na educação: uma análise dos documentos finais das CONAEs, DCNs e PNE. 176 f. 2016. Tese (Doutor em Educação) Universidade Federal do Rio Grande do Sul, Porto Alegre, 2016. Disponível em: https://www.lume.ufrgs.br/bitstream/handle/10183/141971/000992696.pdf?sequence=1\&is Allowed=y. Acesso em: $1^{\circ}$ jun. 2021.

SCARANO, Renan Costa Valle et al. Direitos humanos e diversidade. Porto Alegre: Grupo A, 2018. E-book.

SILVA, Tomaz Tadeu da. A produção social da identidade e da diferença. In: SILVA, Tomaz Tadeu da; HALL, Stuart; WOODWARD, Kathryn (orgs.). Identidade e diferença: a perspectiva dos estudos culturais. Petrópolis: Vozes, 2000. p. 73-102. Disponível em: http://www.lite.fe.unicamp.br/papet/2003/ep403/a_producao_social_da.htm. Acesso em: $1^{\circ}$ jun. 2021.

Recebido em: 05/05/2021

Parecer em: 27/05/2021 Aprovado em: 06/07/2021 